\title{
De Neologismo a Símbolo
}

\author{
Carolina Akie Ochiai Seixas LIMA ${ }^{1}$ \\ $\mathrm{UFMT} / \mathrm{MeEL}$
}

Resumo: Este texto aborda a questão do neologismo no campo semântico da informática, o que nos permite fazer algumas inferências a respeito do que postula Saussure (1989) em seu Curso de Lingüística Geral sobre signo lingüístico. Numa tentativa de relacionar neologismo e signo, o texto em questão aproxima a abordagem teórica apresentada por Santaella (2001) à teoria postulada por Bastuji (1974) a respeito de neologismo.

Palavras-chave: signo, neologismo, símbolo.

Abstract: This text is concerned with the issue of neologism in computing, which allow us to infer about Saussure (1989) thoughts about linguistic sign. As an attempt to connect neologism and sign, this text brings together the theoretical approach presented by Santaella (2001) and Bastuji's theory (1974) about neologism.

Keywords: sign, neologism, symbol.

Resumen: Este texto aboga por la cuestión del neologismo en el campo semántico de la informática, lo que nos permite hacer algunas inferencias con respecto a lo que postula Saussure (1989) en Curso de Lingüistica General acerca del signo lingüístico. En el intento de relacionar neologismo y signo, el presente texto acerca el abordaje teórico presentado por Santaella (2001) de la teoría postulada por Bastuji (1974) con relación al neologismo.

Palabras claves: signo, neologismo, símbolo.

\section{Introdução}

Pensemos no mundo moderno, na globalização, na efervescência tecnológica, na velocidade com que as palavras circulam

\footnotetext{
${ }^{1}$ Aluna regular do Programa de Pós-Graduação em Estudos de Linguagem Mestrado-MeEL da UFMT.
} 
nos meios de comunicação, meios esses que criam sua própria linguagem. Vamos nos ater à linguagem da informática, mais especificamente no que diz respeito aos neologismos apresentados nessa área do conhecimento. Levemos em conta o fato de que o neologismo é um signo, que representa um dado objeto, dessa forma Saussure expõe que 'o signo lingüístico une não uma coisa e uma palavra, mas um conceito e uma imagem acústica' (SAUSSURE, 1989, p. 80), obedecendo a dois princípios, da arbitrariedade do signo e do caráter linear do significante. Percebemos, então, que no caso dos neologismos criados na informática em oposição aos ícones da mesma área que são significantes visuais que podem oferecer complicações simultâneas em várias dimensões, os significantes acústicos (neologismos) acabam formando uma cadeia sonora provocada pelos signos gráficos o que causa a interpretação desejada no ato da leitura.

\section{A Questão Neológica}

Tomemos por neologismo o que diz Bastuji (1974, p. 7): o neologismo é a própria unidade lexical nova. Nesse sentido, existem dois tipos de neologismos: o neologismo comum, que é uma unidade provida de forma e sentido novos, e o neologismo de sentido, que consiste em uma nova acepção para a unidade já constituída. Enquanto o neologismo comum se acomoda à definição saussureana de signo, sendo este "a união indissociável de um significado e de um significante", o neologismo de sentido postula a correspondência biunívoca entre significante e significado.

Para Santaella (2001, p. 261):

Se o signo em si mesmo é um legi-signo, em relação ao objeto que ele representa, esse signo funcionará como símbolo e em relação ao interpretante que deve produzir, o legi-signo simbólico será interpretado como um argumento, princípio de seqüência que segue das premissas até a conclusão.

Dessa forma funcionará o neologismo. Vejamos um exemplo retirado do glossário de informática apresentado no manual de informática da Reader's Digest (2001): 
Fonte Estilo específico de tipologia, como Helvetica ou Times New Roman. A maioria das fontes pode ser exibida e impressa em diferentes tamanhos.

Se tomarmos a palavra Fonte como exemplo de neologismo, perceberemos que esses signo se tornará um legi-signo simbólico que será interpretado como argumento porque ele, por si só, no contexto em que se realiza traduz ao usuário uma representação que difere do uso comum da língua.

No mesmo sentido Santaella (2001, p. 262) cita Ransdell (1983, p. 54): “ “... o legi-signo é um signo considerado no que diz respeito a um poder que lhe é próprio de agir semioticamente, isto é, de gerar signos interpretantes".

Veja o que acontece com o neologismo, qual o seu comportamento dentro do glossário de informática do manual Como fazer quase tudo com o seu computador da Reader's Digest (2001) ou inserido no uso diário por aqueles que trabalham nesse meio. O que ocorre é que este passa a agir semioticamente, gerando, então, outros signos interpretantes.

Assim completa Santaella (2001, p. 262): “A linguagem verbal é o exemplo mais evidente de legi-signo ou sistema de legisignos."

Vejamos o que ocorre com outro exemplo retirado do glossário do manual de informática da Reader's Digest (2001) :

\begin{abstract}
Abrir expor na tela um arquivo ou pasta para visualizar o seu conteúdo. Para abrir um arquivo ou pasta, clique no ícone duas vezes, ou clique com o botão direito do mouse e selecione Abrir no menu pop-up, ou selecione o item, vá para o menu Arquivo e clique em Abrir.
\end{abstract}

A palavra Abrir também se configura como um neologismo, o seu significado neste contexto está no plano do simbólico porque se refere aos procedimentos que o usuário deverá seguir para concluir a ação. Para complementar, vejamos o que diz Peirce (193158), citado por Santaella (2001, p. 263):

O significado que Peirce deu ao termo 'símbolo', o de 'um signo convencional que depende de um hábito nato ou adquirido' (CP 
2.297), não tem nada de novo, pois corresponde a um retorno ao seu significado original.

Percebemos, então, que tanto a palavra abrir quanto a palavra fonte configuram-se como um neologismo semântico, porque, no que se refere à sua estrutura, não houve qualquer mudança; o mesmo não ocorre com o seu significado, dado que o contexto exige tal mudança de interpretação. Para tal, utilizamos a explicação de Peirce, referenciado por Santaella (2001, p. 264) “... não só o símbolo, mas também seu objeto e ainda seu interpretante são todos os três de natureza geral , tipos abstratos." Entendemos, aqui, que o termo neológico funcione como um símbolo, já que o mesmo representa de forma abstrata aquilo ao qual se refere.

Vejamos como Peirce (1931-58) define símbolo:

Defino símbolo como um signo que é determinado por seu objeto dinâmico apenas no sentido de que ele será assim interpretado. Ele depende, portanto, de um nova convenção, um hábito ou uma disposição natural do seu interpretante ou campo do seu interpretante (aquilo de que o interpretante é uma determinação) (CP 8.335). (apud SANTAELLA, 2001, p. 265)

Então, se o neologismo é um símbolo e sendo um símbolo é um signo, não podemos deixar de considerar o seu caráter dinâmico, no que se refere ao seu significado, dado o contexto, teremos a convenção. No caso dos exemplos aqui citados, abrir e fonte, que foram retirados do glossário do manual de informática, já citado, podese perceber nitidamente esse caráter dinâmico do signo, porque, estando os termos referidos dentro de um glossário de uma determinada área da ciência, automaticamente convenciona-se interpretá-los naquele contexto que não o uso comum do termo.

Para complementar tal raciocínio, citamos um trecho do pensamento peirciano abstraído de Santaella (2001, p. 266):

Se o signo simbólico é, em si mesmo, um legi-signo, essa lei é também uma regra geral ou hábito. Ou melhor, não apenas seu interpretante, mas o próprio legi-signo é também um hábito ou regra geral efetiva (CP 2.249). 
Assim, ele aciona o campo do interpretante que produzirá uma associação de idéias gerais que o levará a uma conexão entre o signo e o objeto denotado, que, no nosso caso, refere-se ao neologismo e ao objeto a que este se refere.

Ainda Santaella (2001, p. 266) complementa:

No caso da linguagem verbal, vem daí o caráter geral, social da língua e, ao mesmo tempo, particular, individual do seu uso. As convenções lingüísticas só operam porque os indivíduos de uma comunidade inteira internalizaram hábitos de interpretação. São esses hábitos ou regras que Peirce (1931-58) chamou interpretantes lógicos.

Temos aqui a explicação para os termos neológicos encontrados dentro do campo da informática que se fazem interpretáveis pelo próprio uso sistemático de uma comunidade, no caso, aqueles que têm contato direto com essa área específica, porque é no interpretante que se realiza a associação de idéias necessárias na mente do intérprete para que haja conexão entre signo e objeto, no caso, o neologismo e seu referente.

\section{Conclusão}

Poderíamos citar muitos outros exemplos de neologismos encontrados na área da informática, mas nos detivemos apenas em dois deles porque cremos ser suficiente, aqui, para exemplificar o fato de que o neologismo é um símbolo que denota seu objeto em virtude de existir um hábito que associa sua significação, de acordo com Peirce (1931-58). O conceito peirciano de hábito é muito geral e abstrato, sendo o hábito um sinônimo de lei adquirida ou natural; quando é adquirida por um pacto coletivo, o hábito é convencional. (SANTAELLA, 2001, p. 265)

Enfim, sabemos que muito pode ser estudado a respeito do caráter neológico da língua, tanto no que se refere ao simbólico quanto ao que se refere ao caráter dinâmico do signo, mas o que nos propusemos aqui foi mostrar minimamente o que seria um neologismo no tocante à teoria peirciana de símbolo. Lembrando que, como cita 
Santaella (2001, p. 269) "as línguas humanas relacionam, por meio de associação de idéias, as regras intralingüísticas com as regras do conceito". Assim se relacionam os neologismos dentro da área da informática, por meio de associação de idéias.

\section{Referências Bibliográficas}

BASTUJI, J. Langages: La néologie lexicale. Paris: Didier-Larouse, 1974. p. 7-14.

SANTAELLA, L. Matrizes da linguagem e do pensamento: sonora, visual, verbal. Aplicações na hipermídia. São Paulo: Iluminuras, 2001.

SAUSSURE, F. Curso de Lingüística Geral. São Paulo: Cultrix, 1990.

COMO FAZER QUASE TUDO COM O SEU COMPUTADOR. Trad. Arquitexto Traduções. Rio de Janeiro: Reader's Digest, 2001. 